\title{
Orientalização e Síntese na Lírica de Helena Kolody e Alice Ruiz S
}

\author{
Orientalization and synthesis in the helena kolody and alice ruiz s's \\ lyric
}

Antonio Donizeti da Cruz*

* Universidade Estadual do Oeste do Paraná. Rua Universitária, 2069. Jardim Universitário 85819110 - Cascavel, PR - Brasil, e-mail : adcdacruz@yahoo.com.br

RESUMO: A lírica de Helena Kolody e Alice Ruiz S contribuem para propor (re)significações à obra kolodyana no contexto da Literatura Brasileira. Os temas recorrentes na lírica de Kolody e Ruiz S são o tempo, a solidão, a memória, a efemeridade e permanência, a viagem, entre outros. Com vários livros publicados, antologias e obras completas, Helena Kolody e Alice Ruiz S realizam um fazer poético enquanto busca da síntese, projetada nas formas escolhidas e no enxugamento dos textos. Os poemas sintéticos, tais como os dísticos, tercetos, quadras, epigramas, tankas e haicais (poesia de origem japonesa), são formas poéticas escolhidas pelas poetas.

PALAVRAS-CHAVE: Poesia; Síntese; Helena Kolody; Alice Ruiz S; "tankas e haicais" (Poesia Japonesa).

ABSTRACT: Helena Kolody and Alice Ruiz S's lyric contribute to propose (re) significations in Brazilian Literature context. The recurrent themes into the Kolody and Ruiz S's lyric: the time; the loneliness; the memory; the transitority; the permanency; the travel among others. With a lot of published books, anthologies and complete works, Helena Kolody and Alice Ruiz S while realizes a poetic "doing", looks for the synthesis of her production. She chooses synthetic form poems such as: distiches, tercets, quartets, ephigrams, "tankas and haicais" (Japanese poetry).

KEYWORDS: Poetry; synthesis; Helena Kolody; Alice Ruiz S; "tankas and haicais" (Japanese poetry).

\section{LÍRICA E ORIENTALIZAÇÃO}

Helena Kolody e Alice Ruiz S configuram como nomes representativos da literatura brasileira e centram suas obras em um universo poético e imaginário em que configuram espaços de lirismo, síntese, elaboração estética e construções de "mundos imaginários possíveis", com obras que apresentam o social, o mítico e as configurações de abordagens centradas nos campos da imaginação e da memória. 


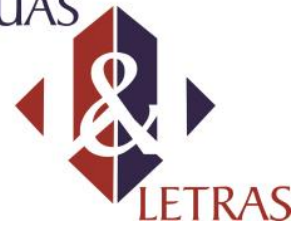

O discurso poético, desde o haikai aos poemas longos, como as epopeias, ou mesmo os poemas em prosa, são potências de uma linguagem capaz de dar sentido à vida. Ao buscar a essência da linguagem, haikaista realiza o poder mágico através das palavras enquanto mediação, comunicação e exercício de construção de sentidos. Assim, o haikai não é simplesmente uma forma de poesia, mas uma maneira de olhar, observar o mundo, isto é, uma filosofia de vida. Em qualquer país do mundo em que há a pratica do haikai, nota-se uma "pintura do haikai", que em forma originalmente como era apresentado o haikai com o haiga e música (shamizem), quer atualmente com os recursos da fotografia ou mesmo pintura, ocorre um entrelaçamento de arte-vida em que se registra um momento único, um flash, tal como afirma Octavio Paz sobre a arte do haikai. Ao se referir ao tanka e haikai, Octavio Paz tece a seguinte afirmação:

o poema clássico japonês (tanka ou waka) compõe-se de cinco versos divididos em duas estrofes, uma de três linhas e a outra de duas: $3 / 2$. A estrutura dual do tanka deu origem ao renga, sucessão de tankas geralmente escrita não por um poeta, mas por vários: 3/2/3/2/3/2/3/2 ... Por sua vez a renga adotou, a partir do século XVI, uma modalidade engenhosa, satírica e coloquial. Esse gênero se chamou haikai no renga. O primeiro poema da seqüência se chama hokku, e quando o renga haikai se dividiu em unidades soltas - seguindo assim a lei de separação, reunião e separação que parece reger a poesia japonesa - a nova unidade poética se chamou haiku, composto de haikai e hokku. A mudança do renga tradicional, regido por uma estética severa e aristocrática, para o renga haikai, popular e humorístico, se deve principalmente aos poetas Arakida Moritake (1473-1549) e Yamazaki Sokan (1465-15539). (PAZ, 1991, p. 198).

Á respeito da orientalização da poesia brasileira Maria da Glória Bordini afirma que: “a poesia e Oriente não são um par recém formado. A atração pelo Leste aflora com certa regularidade em momentos de recusa ao racionalismo e pragmatismo do Ocidente cristão" (1993, p. 91-92). Ela também diz que "já no século XVIII, Voltaire castigava a Europa com a sabedoria ancestral da China. O pré-romantismo enamorou-se pelo exótico, pelo longínquo, na busca por uma origem incontaminada, por um mundo em estado virginal, de homens livres e em perfeita harmonia com a Natureza [...] Mesmo aqui no Brasil, em nossa lírica dos oitocentos, essa fascinação pelo remoto, pelo bom selvagem, talvez impulsionasse o indianismo de Gonçalves Dias, tanto quanto o desejo de estabelecer a identidade nacional num passado ameríndio.” (BORDINI, 1993, p. 91-92). 




A respeito do fenômeno da orientalização da poesia brasileira, Alice Ruiz declara:

[...] a poesia, hoje, não está mais só nos livros, a poesia hoje, até por uma questão de sobrevivência, está no outdoor a poesia está na arte postal, a poesia está na camiseta, a poesia está nos muros, está no telegrama e inclusive a poesia está usando alta tecnologia, também porque se faz poesia com holograma, se faz poesia em vídeo-texto, se faz poesia a laser que dizer, a poesia ela está inovando em nível de veiculação. E não dá para botar um épico numa camiseta, certo, assim um sonetaço numa camiseta ninguém vai ler. Então o haikai, uma forma tradicional do Oriente, que começou mais ou menos no século VIII na corte e que depois foi difundida efetivamente no século XVI e, melhor ainda, no século XVII, só chegou ao Ocidente no século XVIII e, só no século XX, chegou ao Brasil. Essa forma tão antiga que vem lá do passado, essa forma tem um grande futuro entre nós, porque ela é rápida, ela é ágil, ela é dinâmica, ela é como nós estamos, cada vez mais, necessitando de que as coisas sejam. Até por ingerências do cotidiano, do dia-a-dia, enfim da nossa forma de ser (RUIZ, 1993, p. 90).

Alice Ruiz também diz que o tema, "a musa", do haikai é a natureza e tudo que a ela se refere, portanto, a orientalização do Ocidente com tecnologia soaria contraditório, não fosse todos os objetos feitos de elementos da natureza: "Dentro de qualquer sistema operacional, existe um chip. O chip é a estrutura mínima, o núcleo mínimo, a célula mínima com o máximo de informação. Esse chip é feito de sílica, e a sílica é um grão de areia. Então se fui enigmática, me perdoem, mas eu quero deixar a coisa assim como o haikai" (1993, p. 91).

A partir das afirmações de Bordini e Ruiz, é possível dizer que o olhar e a busca pelo incontaminado, refletem na conscientização e na reflexão do poeta sobre a relação do homem com a natureza, e nas práticas zen, já que o haikai em sí só está associado a uma forma de prática zen; o dinamismo e a agilidade do haikai vêm satisfazer o que necessitamos: dar síntese a poesia e colocá-la ao alcance de todos, pois afinal de contas, nos dias de hoje, poucas pessoas têm tempo e vontade de pegar um livro de poesia para ler.

A orientalização da poesia pode ser contatada em obras como Reika, de Helena Kolody e Desorientais (haikais), de Alice Ruiz S, por contribuirem para a sobrevivência e a divulgação da poesia brasileira/oriental, até por que a obra carregada de uma mistura do antigo com o novo, do Oriente com o Ocidente, foi e é bem recebida pelos críticos e leitores. Tanto Reika como Desorientais mantém diálogos entre ocidente e oriente através das reflexões sobre a natureza humana e a contemplação da natureza. Do 
Oriente, Kolody e Ruiz S assimilaram a síntese poética e a essência do natural e zen, contidos no haikai, lançando sobre tudo isso a sua própria visão de mundo interligadas à reflexão poética.

\section{IMAGENS LÍRICAS E SÍNTESE POÉTICA}

HELENA KOLODY nasceu em Cruz Machado (PR). Faleceu em Curitiba, em 2004. Personalidade humana e literária marcante, ela tem uma trajetória poética e social singular. Publicou doze livros de poesia e doze antologias, além de inúmeros poemas publicados em revistas e jornais. Emergiu para a literatura brasileira em 1941, com o livro Paisagem interior, publicado às suas próprias expensas. Publicou também Música submersa (1945); Vida breve (1965); Era espacial (1966); Trilha sonora (1966), tempo (1970); Sempre palavra (1985); Poesia mínima (1986); Ontem agora (1991). A obra reika, publicada em outubro de 1993, por iniciativa de Nivaldo Lopes, reúne vinte e oito poemas (haicais e tankas), marcados pela síntese e brevidade. Desde paisagem interior (1941) passando por Reika (1993) até Tear de palavras, que reúne poemas inéditos (in: CRUZ, 2012. Organizado pela minha pessoa), a poeta concretiza uma trajetória que se revela em uma poesia participativa e harmoniosa.

ALICE RUIZ nasceu em Curitiba (PR). Reside em São Paulo (SP). Estreou na literatura paranaense com a obra Navalhanaliga, em 1980 (recebeu o prêmio de melhor obra editada no Paraná, no referido ano). Em seguida, publicou Paixão xama paixão (ed. da autora); Pelos Pelos (Editora Brasiliense, 1984); Hai-tropikai (em colaboração com Paulo Leminski, pela Ed. Fundo de Ouro Preto em 1985); Rimagens (1985); Viceversos (Ed. Brasiliense - Recebeu o Prêmio Jabuti de 1989); Poesia para tocar no rádio (pela Blocos, 1999); Yuuka (AMEOP, 2004), e outras. A poeta Alice Ruiz traduziu as seguintes obras: Dez hai-kais (Ed. Noa Noa, em 1983), Sendas da Sedução (Ed. Olavo Brás, 1987), e outras. Enquanto Letrista, ela tem parceria com Arnaldo Antunes, José Miguel Wisnik e Itamar Assumpção.

Em 13 de junho de 1993, Helena Kolody e Alice Ruiz S recebem homenagens com as outorgas de nome haicaísta (Alice: Yuuka; Helena: Reika) pela comunidade nipo-brasileira de Curitiba, em comemoração aos 300 anos da cidade e 85 anos da imigração japonesa. 


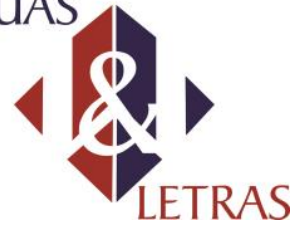

Na literatura brasileira, Helena Kolody e Alice Ruiz S, artistas da modernidade, projetam constantemente no quotidiano a matéria de seus textos (prosa e verso), a realidade entrelaçada à maneira de compor as relações entre poesia e vida. Em relação ao quotidiano e ao olhar fotográfico captado pelo poeta na composição da matéria do haikai tudo uma forma de observação da natureza, da vida, da sociedade, quer nos registros citadinos que na observação atenta à natureza circundante. Constata-se na obra de Helena Kolody e Alice Ruiz S um olhar projetado no cotidiano e nas suas reinvenções, em suas transmutações da realidade convertidas em matéria verbal capaz de refletir e de dar novos direcionamentos à vida e à arte, como bem lembra Paulo Leminski, ao comparar a obra de Kolody e a de Quintana.

Helena Kolody, já em sua primeira obra, Paisagem interior, demonstra uma tendência para a poesia sintética, pois nesta aparecem três haikais publicados que remetem à "poesia-síntese" de origem japonesa. Em relação à arte do haikai, Kolody declara que foi a comunicação com outros centros culturais e, especialmente, o contato com o Jornal de Letras e da correspondência com a escritora paulista Fanny Dupré que teve conhecimento do poema miniatural japonês:

Os literatos e os críticos simplesmente ignoraram essa poesia que ninguém, ainda, estava fazendo no Paraná. No entanto, meus alunos, alunas principalmente, decerto porque eram muito jovens, e os jovens adoram novidades, gostaram muito. Tanto que a turma de 1943, se não me engano, ofereceu-me, como presente de aniversário, seis quadros, em pergaminho, com ilustrações dos três 'hai-kais' de Paisagem interior: três quadros de Guido Viaro e três iluminuras de Garbácio. Meus alunos sempre amaram minha poesia; divulgaram-na pelo Paraná afora. (KOLODY, 1986, p. 27)

Já os haikais de Kolody registram momentos privilegiados na percepção da paisagem do mundo e/ou da realidade comum. Para a poeta Alice Ruiz, "Helena nos mostra, como um mestre zen, que a poesia está nas coisas, é só acertar o olhar”, pois "poesia não é perfumar a flor. Poesia é o perfume da flor. Tal como a poesia de Helena Kolody" (RUIZ, In: HELENA Kolody. 1995, p. 50-51). Com admiração confessa para sua cúmplice em poesia, Ruiz declara que recebeu juntamente com Helena Kolody a outorga de nome haicaísta em 1993. Afirma ainda:

Vivi, com Helena Kolody, a maior homenagem que meu coração de poeta já recebeu. O nome de haicaísta, tradicionalmente dado pela comunidade nipônica aos que se destacam nesta poesia, nos foi outorgado na mesma cerimônia, em 13 de junho de 1993. Talvez, pela primeira vez, para duas ocidentais. Homenagem ainda maior por 
ter sido ao lado de nossa poeta mais amada. Ela, Reika e eu, Yuuka. $\mathrm{O} \mathrm{Ka}$ dos dois nomes significa flor. Os prefixos Rei e Yuu são adjetivos/virtudes específicas da flor. Ambos apontam para formas de grandeza. Superlativos para quem pratica a poesia mínima. [...] Helena é mestra desta grandeza desde 1941, quando publicou seus primeiros haikais, até os dias de hoje, num aperfeiçoamento em que espírito e técnica se fundem para deixar em nós, definitivamente, o perfume da mais autêntica poesia. (RUIZ, In: SINFONIA da vida, 1997, p. 15)

Em suas três primeiras obras Kolody se encaminha cada vez mais para a poesia intimista, confessional e auto-indagadora em que predomina o subjetivismo, a introspecção e o "mergulho" no mundo interior, no qual o eu-lírico vai se desdobrando em imagens, deixando transparecer uma consciência de mundo projetada na questão pessoal e social. A partir de Vida breve verifica-se, ainda mais, a condensação e a síntese, que será a marca atual de sua poesia, ou seja, ocorre uma "progressiva essencialização" (MURICY, [197-], p. 6.) em sua obra, consoante afirmativa de Andrade Muricy. Em relação a evolução de sua poesia, Helena Kolody declara que sua poesia foi "crescendo no sentido da síntese. No meu primeiro livro há poemas com três páginas, eu me derramava muito nas palavras. Hoje busco a síntese para traduzir o pensamento. Os meus melhores livros são aqueles em que digo muito em poucas palavras.” (KOLODY,1985, p. 5).

Entre os primeiros críticos a apresentar a poesia Helena Kolody estão Rodrigo Júnior e Andrade Muricy. Consoante as afirmações de Helena Kolody e a evolução de sua obra, nota-se que na lírica kolodyana ocorre um "enxugamento" dos textos, encaminhando-se cada vez mais para um estilo direto, privilegiando a economia dos meios de expressão. A poeta realiza um fazer poético marcado por uma linguagem densa, sutil, registrando o instantâneo, o fugaz e as coisas mais simples. Tal como o tecelão que vai escolhendo os fios e emaranhando-os no tear, da mesma forma Kolody constrói seus poemas - tecidos de palavras - com precisão e arte.

Para Kolody, o poema surge das impressões apreendidas as quais vão se acumulando no inconsciente. O presente haikai é um exemplo do lirismo kolodyano:

\section{Pereira em flor}

De grinalda branca,

Toda vestida de luar,

A pereira sonha.

(KOLODY, 1945, p. 17) 


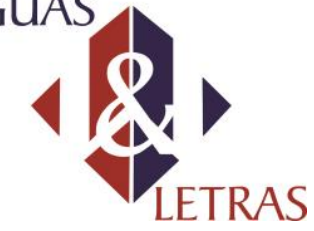

Os versos do poema trazem a personificação da pereira, tal qual noiva, a sonhar. Esta imagem compõe uma tela de singular beleza. A luz da lua, marca a noite, que embala o sonho, de toda jovem pereira. Elogiado por Carlos Drummond de Andrade, este haikai alude ao caráter efêmero da existência. Helena Kolody descreve como surgiu o poema:

\begin{abstract}
Eu morava na Rua Carlos de Carvalho. Uma noite, ao sair da casa de uma amiga, dei com aquela pereira completamente florescida, banhada pela luz da lua cheia. A beleza do quadro foi um impacto na minha sensibilidade. Fiz o poema bem mais tarde. Associei a pereira com a noiva: a noiva toda vestida de branco, sonhando, como a pereira ao luar. (KOLODY, 1986, p. 22)
\end{abstract}

No que diz respeito ao ato criador de Helena Kolody, pode-se dizer que ele é um processo que se operacionaliza de maneira organizada, através das observações atenta da natureza com o mundo circundante vivenciado pela poeta.

A obra Reika, de Helena Kolody, publicada em outubro de 1993, reúne 28 poemas (haikais e tankas), marcados pela síntese e brevidade que apontam para a sutileza das imagens, para a manifestação da natureza, em que a poeta capta o instantâneo, o momento único, engendrado por uma "lumino-transparência". Os haikais e tankas de Kolody deixam transparecer momentos tensos e transparentes, que se direcionam à observação da natureza.

A temática de Reika trata também, de maneira reiterada, da questão do tempo e suas relações subentendidas, da observação do elemento sazonal, da solidão e da metapoesia.

O haikai "Saudades", de Kolody, apresenta um lirismo nostálgico, com uma linguagem lúdica, metafórica e organizada e com um tênue acento de melancolia:

\author{
Saudades \\ Um sabiá cantou. \\ Longe, dançou o arvoredo. \\ Choveram saudades. \\ (KOLODY, RE, 1993, p. 21)
}

Esse haikai miniatural apresenta a saudade e a natureza interligadas, pois o canto do sabiá, mesmo distante, é capaz de despertar o sujeito para uma observação atenta da natureza. Na primeira estrofe, a constatação do canto do sabiá direciona os versos seguintes. $\mathrm{O}$ canto funciona como um circuito entre o pássaro, as árvores e a saudade. $\mathrm{O}$ tema da saudade está ligado ao da memória, pois "chover saudade" é uma forma de 
rememorar, de lembrar as coisas que ficaram "adormecidas" em outro tempo distante. Daí o vetor da memória: cintilações de lembranças e esquecimentos, pois como bem lembra Bachelard, "o homem mira-se no seu passado, toda imagem é para ele uma lembrança" (BACHELARD, 1989, p. 69).

A viagem também é tema do haicai intitulado "Depois". O momento presente inquieta o eu-lírico que sabe de sua situação enquanto "viajante das galáxias", ao afirmar:

\section{Depois}

Será sempre agora.

Viajarei pelas galáxias

universo afora.

(KOLODY, RE, 1993, p. 25)

A temática da transitoriedade do ser se faz presente nos versos do poema. A inserção na temporalidade, cuja afirmação do eu-lírico é reiterada pelo sintagma "sempre agora", revela uma escrita em que o regime dialético se dá na aceitação do fluir temporal e no reconhecimento do processo permanente de transformação vital. Os versos do poema indicam que o espaço terrestre não basta para o "viajante"; esse precisa deslocar-se pelo universo "afora" para transpor o "agora".

O haicai "No mundo da lua" acentua o tom afirmativo no que se refere à combinação e ao dinamismo da linguagem. O eu-lírico declara sua condição de caminhante e sonhador:

\section{No mundo da lua}

Não ando na rua.

Ando no mundo da lua, falando às estrelas.

(KOLODY, RE, 1993, p. 31)

São versos que mostram a imaginação do sujeito poético, capaz de articular a linguagem de maneira lúdica. Há, nos versos, o afastamento da realidade cotidiana, através da negação de andar à rua. O eu-lírico afirma divagar no mundo da lua e conclui revelando seus interlocutores: as estrelas. O verbo no gerúndio dá uma ideia de movimento aos versos. Nota-se que o "andar no mundo da lua" tem sentido figurado, de sonhar, de desligar-se da realidade imediata. 


\section{"JOTnada" é m}

"Jornada" é mais um haicai voltado para a temática do tempo, da viagem que aponta para a vida e para a morte. O poema, com seu tom lúdico e miniatural, expressa todo um pensamento elaborado:

\section{Jornada}

Tão longa a jornada

E a gente cai, de repente,

No abismo do nada.

(KOLODY, RE, 1993, p. 41)

No primeiro verso do poema, o tempo aparece representado por uma conotação metafórica, pois a palavra "longa" remete à duração temporal da jornada. Em contrapartida, o sintagma "de repente" contrasta com o primeiro segmento do poema. Os versos "e a gente cai, de repente/ no abismo do nada" denunciam que a vida, sem consulta prévia, prepara para todos, o desfecho. $\mathrm{O}$ verbo cair aponta para a condição da transitoriedade humana. No dizer de Morin, "o homem traz consigo o mistério da vida, a qual por sua vez traz consigo os mistérios do mundo" (MORIN, 1988, p. 327).

No haicai "Desafio", o sujeito lírico declara que os obstáculos que impedem a passagem podem servir de estímulo para novas buscas:

\section{Desafio}

A via bloqueada instiga o teimoso viajante a abrir nova estrada.

(KOLODY, RE, 1993, p. 35)

Nos versos, a vida torna-se personagem da odisséia da aventura de construir novas perspectivas. A estrada é símbolo de viagem e transitoriedade do ser que está sempre em busca de realizações.

No tanka intitulado "Sabedoria", apresenta-se a temática do efêmero, da brevidade da vida, do tempo e da saudade:

\section{Sabedoria}

Tudo o tempo leva.

A própria vida não dura.

Com sabedoria, colhe a alegria de agora para a saudade futura.

(KOLODY, 1993, p. 61) 




O sujeito poético descortina o tempo que passa e leva o "tudo" para o nada. A alegria presente no texto direciona à brevidade da vida. A alegria, armazenada na lembrança, pode ser a energia que permitirá o longo percurso para o futuro, em que ocorre a questão essencial: o ser humano tem um tempo a cumprir na existência. Por isso, a necessidade de se viver intensamente o presente, ou seja, é necessário buscar com sabedoria "a alegria de agora", tendo em vista "a saudade futura". Os versos do tanka se voltam para a temática da brevidade da vida. A imagem do tempo, que tudo arrasta consigo, faz com que o sujeito lírico lance o olhar para o tempo futuro. Registrase ainda, o alto teor de "esperança", relacionado ao tempo presente, acentuando o carpe diem horaciano, marcado pelo alto teor de "esperança", relacionado ao tempo presente, acentuando o carpe diem horaciano. A efemeridade da vida é realçada através da imagem "tempo", que arrasta todas as coisas. A efemeridade da vida é realçada através da imagem "tempo", que arrasta todas as coisas. Assim, o tanka direciona-se para a temática da brevidade da vida. A imagem do tempo, que tudo arrasta consigo, faz com que o sujeito lírico lance o olhar para o tempo futuro.

Em 13 de junho de 1993, Helena Kolody e Alice Ruiz recebem homenagens com as outorgas de nome haicaísta (Alice: Yuuka; Helena: Reika) pela comunidade nipo-brasileira de Curitiba, em comemoração aos 300 anos da cidade e 85 anos da imigração japonesa (CRUZ, 2001, p. 190-191). Com admiração confessa para sua cúmplice em poesia (Helena Kolody), Ruiz declara,

Vivi, com Helena Kolody, a maior homenagem que meu coração de poeta já recebeu. $\mathrm{O}$ nome de haicaísta, tradicionalmente dado pela comunidade nipônica aos que se destacam nesta poesia, nos foi outorgado na mesma cerimônia, em 13 de junho de 1993. Talvez, pela primeira vez, para duas ocidentais. Homenagem ainda maior por ter sido ao lado de nossa poeta mais amada. Ela, Reika e eu, Yuuka. O Ka dos dois nomes significa flor. Os prefixos Rei e Yuu são adjetivos/virtudes específicas da flor. Ambos apontam para formas de grandeza. Superlativos para quem pratica a poesia mínima (RUIZ. In: VENTURELLI, 1995, p. 50-51)

Sobre a poesia de Alice Ruiz, a poeta Helena Kolody tece a seguinte afirmação a respeito do fazer poético e dos haikais de Ruiz,

Em poesia, mais importante do que aquilo que se diz, é a maneira como se diz. O dizer poético de Alice Ruiz é personalíssimo e, ao mesmo tempo, universal. Não é só a poesia sintética, aprisionando em poucas palavras o essencial, que a distingue. É a magia das palavras, soltas como pássaros, no branco vibrante da página. Artista consumada, Alice trabalha com perfeição a filigrana japonesa do hai- 




kai, captando, sutilmente, os imponderáveis poéticos. Uma de suas características é o comedimento. Mesmo nos poemas confessionais, mais sugere do que diz, exigindo a colaboração inteligente do leitor (KOLODY, In: ALICE RUIZ, 1997, Contra-capa, Série paranaense).

Alice Ruiz, em homenagem à Helena Kolody, presenteia a poeta pela passagem de aniversário, em 1987, com seus "hai-kais discípulos" (RUIZ, 1987. p. 18.), publicados no Correio de Notícias:

\author{
RENGA \\ para Helena Kolody \\ a primeira a fazer hai-kai \\ por aqui \\ quanto mais longe vejo \\ mais luzes ficam \\ até o próximo reflexo \\ primavera \\ até a cadeira \\ olha pela janela \\ primeira folha de outono \\ no chão começa \\ o meio do ano \\ longe hoje \\ você me quer pra ontem \\ e só vem amanhã \\ entre a terra e a lua \\ minha alma \\ tua
}

A respeito da poesia de Alice Ruiz, Marilda Binder Samways, em Introdução à literatura paranaense, faz a seguinte afirmação:

Alice Ruiz possui uma poesia contundente e renovadora tanto nos aspectos temáticos como nos formais, principalmente nos formais, pois ela aproveita a lição das vanguardas e desestrutura o verso tradicional, construindo suas idéias a partir da fragmentação do homem moderno. Talvez a mais importante preocupação de Alice seja com a posição humana e social da mulher, vista sob diferentes ângulos: o erótico, o amoroso, o lírico, a maternidade, o ser que se sente marginal no processo econômico e que busca realçar sua posição, descobrindo novos valores e exigindo a transformação dos esquemas sociais convencionais dominados pelo homem. Não que a poesia de Alice Ruiz seja dominantemente indagadora desses problemas, mas eles aparecem como resultado das próprias posturas assumidas pela artista (SAMWAYS, 1988, p. 131) 


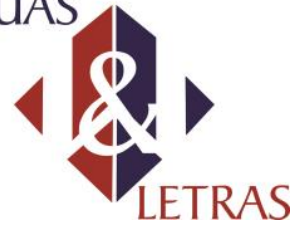

Luiza Maria Lentz Baldo, em Fotografia do cotidiano: a consagração do instante em Rubem Braga e Alice Ruiz, tece a seguinte afirmação sobre a poesia de Alice Ruiz,

\begin{abstract}
A poeta curitibana Alice Ruiz (1946) conta que foi Leminski, seu companheiro por quase vinte anos, quem, em 1968, a apresentou ao haicai. Afora a influência do marido, a poeta ressalta a do Concretismo que representou o que ela qualifica como uma "escola de liberdade", uma vez que os concretistas abriram os olhos das pessoas para a materialidade da linguagem. Além da poesia oriental e da concreta, a artista reconhece a poesia simbolista como algo que, se não chegou a ser uma influência direta, a fascinou, pois, além de ter sido o que a poeta concebe como "uma espécie de praga" em Curitiba, foi um momentos de maior presença literária do Paraná no cenário nacional (BALDO, 2006, p. 71).
\end{abstract}

Baldo destaca ainda que em vários haikais de Alice Ruiz ocorrem a presença "nítida" do eu-lírico, "imprimindo-lhes certa subjetividade, o que não implica em perda de qualidade, ao contrário, uma vez que, até mesmo em Bashô, algumas vezes o pessoal torna-se perceptível como no haicai: 'Ah! kandodori/ Tu aprofundas/ Minha solidão", podendo, assim, ser notada "o caráter subjetivo do poema" [e a referência ao tema da solidão]. (BALDO, 2006, p. 71).

A obra Desorientais (1998), de Alice Ruiz S, chama atenção pelo nome, além é claro do fato de ser um livro inteiramente composto por poemas de modelos japoneses como o caso dos haikai, rengas e tanka (poemas de origem japonesa). Alice Ruiz S tece o seguinte comentário sobre o título do livro: "desorientais porque: não existiriam sem as pessoas e toda sua complexidade, ao contrário dos orientais feitos apenas com a simplicidade das coisas. São versos feitos para, com e por causa desse outro, onde o eu aparece impregnado de nós, ao contrário dos orientais, onde o eu se retira para que tudo seja apenas como é.” (RUIZ, 1998, p. 19).

Desorientais apresenta-se tripartidas em: "Eus", "Eles Elas Elos", "Eros”. A parte "Eus" configura-se na tessitura de poemas que estão direcionados aos desdobramentos do "eu"; "Eles Elas Elos" mostram poemas dedicados e direcionados aos amigos e membros da família de Alice Ruiz S, e em "Eros" exalta-se o discurso relacionado ao tema do amor.

O texto intitulado " tanka” (o único que aparece na obra Desorientais), com sua imagem do peixe que vai para o mar após pular na mão e ser devolvido ao mar. Aqui sujeito da enunciação e natureza estão imbricados pois um depende do movimento do outro quer para a vida quer para os agitações do mar: 



Nota-se o fluxo da vida expresso no seguinte enunciado: "ainda que você me deixe/viver nos move", com sua força vital, mesmo apresentando a perda há que se continuar o viver.

No haikai "primeiro vagalume", apresenta-se a observação do sujeito da enunciação em relação à natureza circundante:

$$
\begin{aligned}
& \text { primeiro vagalume } \\
& \text { assim começa } \\
& \text { o fim do ano } \\
& \text { (RUIZ S, 1998, p. 23) }
\end{aligned}
$$

O ciclo vital está relacionado à forma como o sujeito da enunciação perceber o vagalume que sinaliza o fim do ano e aponta para o kigo (haikais que apresentam imagens interligadas às quatro estações e à natureza).

No haikai "manhã de sol", o sujeito poético traz à tona as lembranças ao ouvir o som da chuva. Vida e natureza se complementam:

$$
\begin{aligned}
& \text { manhã de sol } \\
& \text { na lembrança } \\
& \text { o som da chuva } \\
& \text { (RUIZ S, 1998, p. 56) }
\end{aligned}
$$

O texto mostra o contraste sol/chuva e as lembranças que marcam os momentos vivenciados mediante o som da chuva. O haikai traz o registro do dinamismo e dos contrastes. Como tudo que é marcado pela dinamicidade, as imagens movimentam-se em um jogo de contrários para encontrarem-se na sensibilidade do sujeito poético. Chuva e sol alternam luz, claridade versus sombra, escuridão. No poema miniatural como o haikai, a palavra sintética movimentam a magia e encantamento de um lirismo expresso pela voz do sujeito da enunciação, em que a palavra poética sustenta o momento fotográfico marcados equilíbrio das imagens que se contrastam e até mesmo se complementam na alternância entre a manhã de sol e o som da chuva.

No renga (haikais encadeados), a seguir, mostra-se a simbiose lar/natureza: 


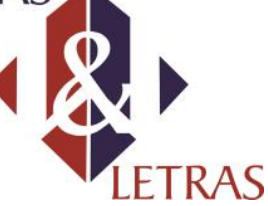

noite fria
na sopa da filha
o calor da mãe

para teu sono uma canção de ninar da chuva e do mar

p/ Aurea Alice Leminski

(RUIZ S, 1998, p. 85)

Dedicado à Áurea, filha de Alice Ruiz, os haikais trazem como tema o amor materno, bem como a valorização da natureza, com imagens da chuva, do mar, da noite fria. São versos que condensam vários sentidos em um espaço gráfico mínimo. $\mathrm{O}$ haikai é uma das formas literárias que mais requer introspecção por parte dos operadores da linguagem e também dos leitores. A singularidade da poesia não surge somente das ideias ou atitudes do poeta, mas acima de tudo de sua voz, ou seja, ele faz do poema um ato, uma construção se sentidos e uma forma de ver e relacionar-se com a natureza.

O Renga abaixo (haikais), de Alice Ruiz S é dedicado à Estrela (filha de Alice Ruiz S e Paulo Leminski):

menina estrela
à beira do mar
persegue a lua

olhos verde cana

cabelos cor de mel

doce de menina

olhos de ver Venus

mesmo fechados

cintilam verdes

p/ Estrela Ruiz Leminski

(RUIZ S, 1998, p. 84)

O sujeito poético constrói um discurso poético centrado na brevidade, no aspecto lúdico da linguagem e na forma de contemplação/olhar direcionados à natureza. As imagens poéticas estão em sintonia com a maneira como o eu poético constrói o poema quer na evocação da "menina estrela" quer na comparação dos elementos da natureza e da vida. 


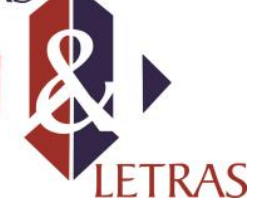

Em "Renga da Noite", o sujeito da enunciação aponta para os elementos da natureza ao falar de si em que ocorre a subjetividade lírica e as imagens da noite com suas várias faces relacionadas ao tempo e ao olhar de contemplação frente à passagem temporal:

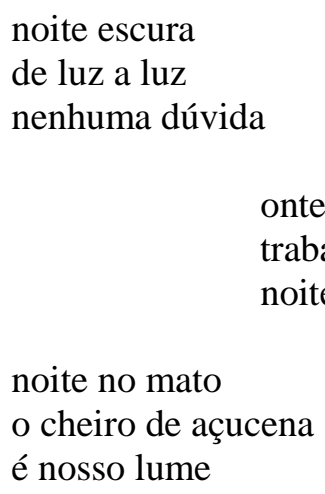

noite no mato

o cheiro de açucena

é nosso lume

noite de verão

escrevendo vento

eu e o vento

\author{
noite de verão \\ vem com a brisa \\ um cheiro de primavera
}

noite no escuro

pensando que era barata

matei o vagalume

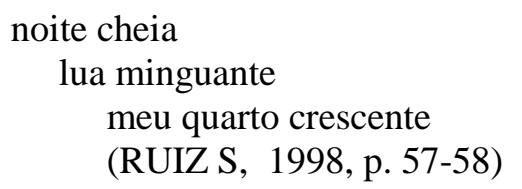

Tanto os rengas quanto à noite, percebe-se o encadeamento numa sucessão de eventos relacionados ao kigo (o verão). O espaços do quarto (crescente) opõe-se à fase da lua minguante. Assim, a noite traz suas formas mais variadas ligadas ao tempoespaço.

\title{
CONCLUSÃO
}

Os poemas sintéticos (tankas e haicais) de Helena Kolody e Alice Ruiz S, são marcados pela brevidade e pela concentração intensa de uma linguagem esteticamente organizada. Neles, as poetas instauram um jogo de cumplicidades com o leitor. No olhar 


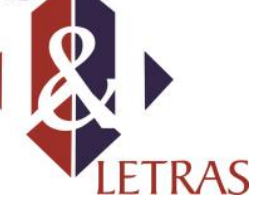

do poeta e do leitor, a linguagem ganha contornos e se torna "poesia-revelação". Nesse sentido, a poesia de Kolody e Ruiz S operam como "caminho-síntese" de uma tensa jornada em busca do eu-outro-cosmo. Daí a relação e valorização da natureza circundante e a serenidade a sublimar

A orientalização na lírica de Helena Kolody e Alice Ruiz S apresenta um diálogo intenso da tradição ocidental com a oriental, tendo em vista a acentuação de uma forma de otredad em relação à valorização da poesia brasileira/oriental, até por que a obras trazem marcas de uma construção poética em que o tradicional e a inovação se mesclam, em o Oriente com o Ocidente mantém correspondências com as reflexões sobre a natureza e a arte do haikai. Do oriente, Kolody e Ruiz S assimilaram a síntese poética e a essência de uma observação/contemplação da natureza centrados nos registros de um fazer poético embasado na força da linguagem sintética e na sintonia de eu/natureza/mundo e de um olhar de contemplação.

\section{REFERENCIAS}

ALICE RUIZ. Curitiba: Editora da UFPR, 1997 (Série paranaense).

AN ANTHOLOGY of Haiku Ancient and Modern. Trad. Asataro Miyamori. The Chugai Printing. 1932.

BACHELARD, Gaston. A água e os sonhos: ensaios sobre a imaginação da matéria. Trad. Antonio de Padua Danesi. São Paulo: Martins fontes, 1989.

BALDO, Luiza Maria Lentz. Fotografia do cotidiano: a consagração do instante em Rubem Braga e Alice Ruiz. Londrina, 2006. Dissertação (Mestrado em Letras) Programa de Pós-Graduação em Letras da Universidade Estadual de Londrina, 2006.

BORDINI, Maria da Glória. A orientalização da poesia brasileira. In: VI Jornada Nacional de Literatura. Passo Fundo: UPF, 1993.

CRUZ, Antonio Donizeti da. O universo imaginário e fazer poético de Helena Kolody. Cascavel: Edunioeste. 2012.

HELENA Kolody. (Org. por Paulo Venturelli). Curitiba: Ed. da UFPR, 1995

KOLODY, Helena. Música submersa. Curitiba: Escola Técnica de Curitiba, 1945. Impresso na Artes Gráficas da Escola Técnica do Paraná.

KOLODY, Helena. In: JORNAL do livro, Curitiba, n. 7, abr./ jun. 1985, p. 5

KOLODY, Helena. Um escritor na Biblioteca: Helena Kolody. Curitiba: BPP/SECE, 1986.

KOLODY, Helena. SINFONIA da vida: Helena Kolody (Antologia poética organizada por Tereza Hatue de Rezende). Curitiba: Pólo Editorial do Paraná - Letraviva, 1997.

KOLODY, Helena. Viagem no espelho. 5. ed. Curitiba: Editora da UFPR, 1999.

KOLODY, Helena. Reika. Curitiba: Fundação Cultural de Curitiba: Ócios do ofício, 1993 (Série Buquinista).

LEMINSKI, Paulo. Distraídos venceremos. 5. ed. São Paulo: Brasiliense, 1987.

MORIN, Edgar. O homem e a morte. Mira-Sintra: Europa-américa, 1988,

MURICY, Andrade. RUMO paranaense, Curitiba, ano II, n. 35, nov. [197-], p. 6 


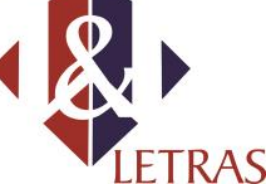

e-ISSN: 1981-4755

DOI: $10.5935 / 1981-4755.20160007$

PAZ, Octavio. Convergências: ensaios sobre arte e literatura. Trad. Moacir Werneck de Castro. Rio de Janeiro: Rocco, 1991.

RUIZ, Alice. A orientalização da poesia brasileira. In: VI Jornada Nacional de Literatura. Passo Fundo: UPF, 1993.

RUIZ, Alice. "Helena querida". In: ROMARIA à padroeira da poesia. Correio de Notícias, Curitiba, 2 out. 1987.

RUIZ, Alice. In: HELENA Kolody. (Org. por Paulo Venturelli). Curitiba: Ed. da UFPR, 1995.

S RUIZ, Alice. Desorientais (hai-kais). São Paulo: Iluminuras, 1998.

Data de recebimento: 20/11/2016

Data de aprovação: 28/11/2016 